\title{
JOB SATISFACTION AMONG PHYSICIANS IN BULGARIAN GENERAL PRACTICE
}

\author{
B. Parashkevova ${ }^{1 *}$, J. Marinova ${ }^{1}$, S. Simeonov ${ }^{2}$, V. Slavova ${ }^{1}$ \\ ${ }^{1}$ Medical Faculty, Trakia Univesrity, Stara Zagora, Bulgaria \\ ${ }^{2}$ National Health Insurance Fund, Branch Stara Zagora, Bulgaria
}

\begin{abstract}
Research on the professional satisfaction of doctors is especially relevant today, in relation to the crisis with medical staff. The purpose of this article is to study the factors of job satisfaction of general practitioners.

An empirical sociological survey was conducted among general practitioners in the Stara Zagora region. The method used is a face-to-face interview. The approved Warr-Cook-Wall (WCW) toolkit is implemented - a questionnaire modified by the research team.

The study includes 223 general practitioners, which determines the high responsiveness: $94.9 \%$. The results show that GPs are mostly satisfied with the factors related to the autonomy of the profession. The clinical freedom defined as the ability of general practitioners to choose the method of treatment of their patients is assessed to the greatest extent as satisfactory. Physicians are most dissatisfied with the regulatory framework they have to comply with and with the constant change of activities required in their daily practice.

The questionnaire for the assessment of job satisfaction of GPs is applied for the first time among Bulgarian physicians. This assessment is useful for the formation of policies for human resource management in health care, as it identifies adverse trends and leads to certain solutions. Models of professional satisfaction influence the professional behavior, important for staying and leaving certain medical area and the emerging shortage of doctors in some specialties.
\end{abstract}

Key words: job satisfaction, general practitioners, dimensions of professional satisfaction, empirical sociological research.

\section{INTRODUCTION}

Human resources are the core of any health system. They are a capital asset and investment in the future to achieve health objectives. The component, which can facilitate or incapacitate the achievement of the objectives of each health care system, is the primary care. At this level, it is possible to use efficiently the limited financial resources in order to achieve a better result in health protection and improvement. Primary care in Bulgaria is based entirely on the work of general practitioners (GPs). Bulgarian problems in primary care, related to the deficit of medical personnel, have arisen. This issue is necessary to be discussed in the

*Correspondence to: Assoc. Prof. Boryana Parashkevova, MD, PhD, Department of Social Medicine and Health Care Management, Faculty of Medicine, Trakia University, 6000 Stara Zagora, Mobile: +359/898259905, E-mail: boriana@mf.uni-sz.bg light of one of the important aspects of career development - job satisfaction. Job satisfaction is defined as the most important result of a successful career. It influences doctors' professional conduct with great impact on whether to continue or quit their relevant medical specialty or level of health service.

A large number of studies look at different aspects of a physician's career: professional trajectory, plans for the future (staying or leaving the profession), continuous education, family life, etc. A silver line present in all these studies is Job Satisfaction (JS) among physicians.

Knowledge of JS is thus of crucial importance for forming healthcare and human resources policies. JS is a complex function of many variables. A lot of those are purely subjective. Psychology and management are helping 
understand JS, initially in the field of Eupsychian Management. According to P. Spector (1) JS is generally the level at which people like or dislike their job. This is of importance for the employers, since they too want their employees to be happy, content and more productive $(1,2)$. L. Diaz-Sereno and J.A. Cabral-Vieira consider JS to be a function of a person's overall wellbeing (3). The studies of JS go back to the 1930's with different authors using different components and interrelations for defining the issue $(2,4)$

Some point out to two different factors: personal and organizational (5). Personal factors include demographics, values and motivation. Organizational factors comprise organizational and legal matters, working place conditions, remuneration and prospects for career development (5). Some studies even propose that JS is connected to personal characteristics like intro or extroversion, tolerance or dedication (6).

Given the ongoing shortages of medical personnel in many European countries, the studies of the level of satisfaction among physicians are even more important for the planning and implementation of new policies in the management of healthcare.

\section{PURPOSE}

Assessment of the factors contributing to job satisfaction among general practitioners in the Stara Zagora region, Bulgaria

\section{MATERIALS AND METHODS}

Sociological survey conducted among GPs in the Stara Zagora region, Bulgaria in the time period July-December 2012. The data was collected by means of a face-to-face interview with a semi-structured questionnaire. The interview included six different sectors, one of which was the study of job satisfaction using the WCW scale. A total of 223 GPs were interviewed, out of total of 235 working in the region. Respond rate is $94.9 \%$. All GPs have contracts with the National Health Insurance Fund, branch Stara Zagora. All of them are owners of practices for primary outpatient care.

For the statistical analysis, descriptive statistics were used along with non-parametric linear correlation, multiple regression analysis, Mann-Whitney test, Kruskal-Wallis test, $\chi^{2}-$ test, Dunn post-hoc test, etc. calculated with SPSS Statistical Software ver. 13.
PARASHKEVOVA B., et al.

\section{RESULTS AND DISCUSSION}

GPs working in the Stara Zagora region are one of the largest GP groups in the country. The average age is 49 years (Range $=32-81$ years, Mode $=45$ years). Largest number of GPs is aged 45 to 54 years. There is only one doctor in the group younger than 35 years. The majority of them are the female : $62.8 \%$.The average years of professional experience of the participants are $22.9(\mathrm{SD}=7.29, \min =9, \max$ $=52$ ) at the moment of the survey. GPs are working mainly in individual (solo) practices (92\%). Group practices are extremely rare which is typical for the rest of the country as well. Nearly $20 \%$ of the GPs are working in adverse (unfavourable) practices, identified as such according to the criteria adopted by the National Health Insurance Fund. GPs receive additional financial incentives when working in such practices. The average patient list of a typical GP is 1484 patients.

Professional development, medical specialization and the quality of healthcare are influenced by job satisfaction. It is the most important result of a successful career. Job satisfaction of health professionals and doctors, in particular, has been researched in many countries and generally, the questionnaire of P.Warr, J. Cook and T.Wall is administered (7). The questionnaire contains 16 components, most of which concern the subjective aspects of personality: extroversion / introversion, neuroticism and others. Initially it was applied to non-health related professional groups. In the late $80 \mathrm{~s}$ the questionnaire was modified to correspond to the medical profession. Established researchers such as B. Sibald et al, and S. Simoens et al, modify this scale according to the characteristics of health professionals and the needs of health care (8-11). The toolkit becomes popular as the Warr-Cook-Wall questionnaire (WCW-scale), on the names of the first researchers. From the beginning of the 90s and till now it has been intensively used in studies among physicians in many countries (12-16). We modified the WCW by excluding the item "remuneration", considering it inappropriate." The modified WCW-scale in our study contains eight items, reflecting the following dimensions of job satisfaction among Bulgarian GPs:

- Weekly working hours;

- Freedom to choose clinical methods of diagnosis and treatment (Clinical Freedom); - Workload; 
- Physical working conditions;

- Variety in the activities performed;

- Professional knowledge and ability

confidence;

- Regulatory framework;

- Continuous education and promotion opportunities.

The questionnaire used is a modified 8 component Warr-Cook-Wall (WCW) with a 5 point Likert scale - 1 - very dissatisfied; 2 dissatisfied; 3- neither satisfied nor dissatisfied (neutral) ; 4 - satisfied; 5 - very satisfied.
This leaves a total of 8 items and Cronbach's alpha coefficient of 0.833 , meaning the reliability of the scale after the modification is very good.

The average scores of items were determined after quantitative scoring from 0 to 100 factors of satisfaction - average values with $95 \%$ confidence interval. Each item in the WCW scale was quantitatively assessed and scored from 0 to 100 .

Table 1. Items in the WCW scale for physicians job satisfaction - means, standard deviations and percentage of satisfaction -- \% of Dissatisfied(very dissatisfied doctors and dissatisfied doctors); \% of Satisfied (satisfied and very satisfied)

\begin{tabular}{|l|l||l|l|l|}
\hline Items & $\begin{array}{l}\text { Means } \\
\text { Scoring) }\end{array}$ & SD & $\begin{array}{l}\% \\
\text { Dissatisfied }\end{array}$ & $\begin{array}{l}\% \\
\text { Satisfied }\end{array}$ \\
\hline Weekly working hours & 57,80 & 27,50 & 23,90 & 52,90 \\
\hline Clinical freedom & 62,40 & 28,30 & 19,30 & 56,10 \\
\hline Workload & 38,20 & 27,90 & 49,40 & 21,00 \\
\hline Physical working conditions & 54,80 & 28,70 & 26,90 & 44,80 \\
\hline $\begin{array}{l}\text { Variety in the activities } \\
\text { performed }\end{array}$ & 35,00 & 27,90 & 57,80 & 17,90 \\
\hline $\begin{array}{l}\text { Professional knowledge and } \\
\text { ability confidence }\end{array}$ & 52,40 & 28,60 & 30,90 & 41,20 \\
\hline Regulatory framework education and & 35,40 & 28,70 & 55,70 & 21,90 \\
\hline $\begin{array}{l}\text { Continuous edo } \\
\text { promotion opportunities }\end{array}$ & 25,70 & 55,60 & 15,30 \\
\hline
\end{tabular}

Regulatory framework has the lowest mean (34.90), and Clinical Freedom the highest (62.40). Working conditions have the highest SD (28.7).

Job satisfaction of the weekly working hours Working hours for the GPs are mainly office hours per week. The number of hours is not strictly fixed, but the GPs have to report their weekly schedule to the Regional Health Insurance Fund. This explains the high level of satisfaction regarding working hours per week (mean 57.8), as well as the high satisfaction percentage $52.9 \%$ (this include satisfied and very satisfied). The dissatisfied (dissatisfied and very dissatisfied) are $23.9 \%$ (Figure 1).

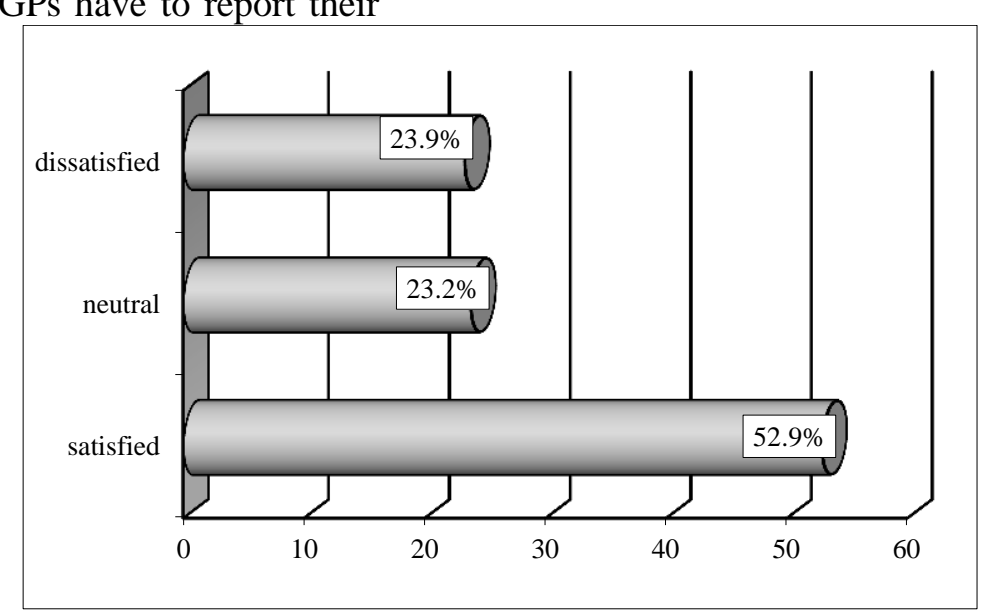

Figure 1. Satisfaction of the weekly working hours - $\%$ of satisfied and $\%$ of dissatisfied 
There is a small negative correlation ( $\mathrm{r}=$ 0.156 , with nonparametric correlation analysis) between JS with working hours and job experience. The GPs with less job experience evidently look more favorably at the working hours than their older colleagues. This may be a sign of the "burnout syndrome" so common in the medical profession (17). There is a statistically significant difference in this item and the type of GP office structure - individual or collective practice $(\mathrm{p}=0.031$, MannWitnney test). The GPs in the collective practices have better working schedules, which indicate a need for furthering of the "équipe" or team practices. There is also a weak correlation between working hours and the number of patients $(\mathrm{r}=-0,132$, with nonparametric analysis). JS is higher with the GPs with fewer patents.

\section{Job satisfaction of the clinical freedom}

Clinical freedom in the context of this study is to choose clinical methods for diagnosis and treatment (Figure 2).

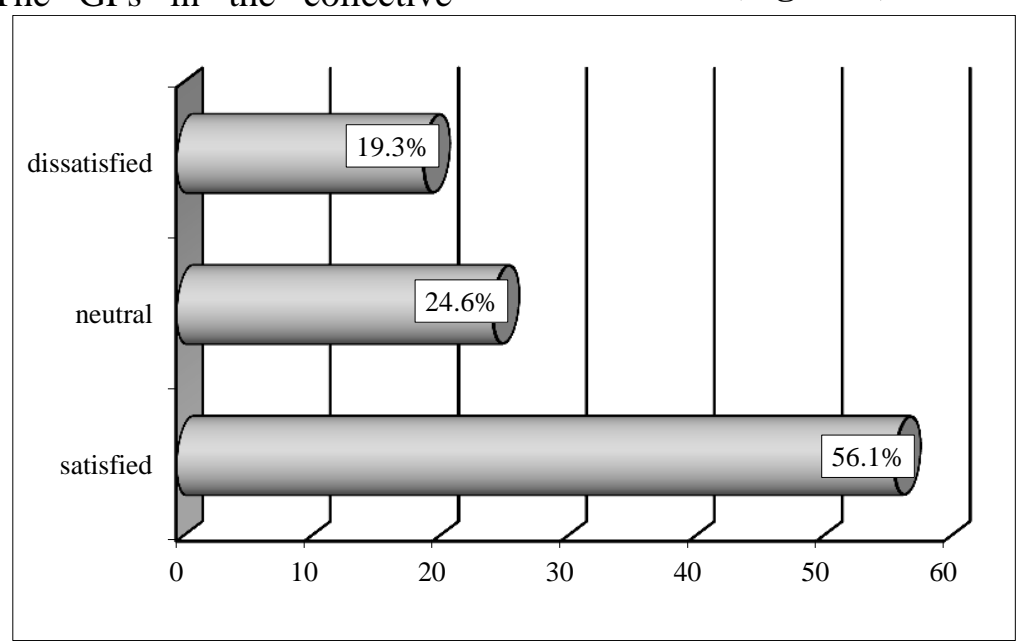

Figure 2. Satisfaction of the clinical freedom - \% of satisfied and \% of dissatisfied

More than half of the respondents are satisfied $(56.1 \%)$ and almost a fifth $(19.3 \%)$ are not. The mean value for this item (62.4) is the highest among all the items. Clearly, this is an important factor in overall job satisfaction. The item has repercussions on the autonomy of the physicians, which is limited by a variety of factors - administrative, regulatory, patient's own will as well as the general structure of the healthcare system. Some of the GPs tend to append their treatment methods with alternative ones - homeopathy, Schuster salts, etc. (18). There is also statistical difference between male and female practitioners $(\mathrm{p}=$ 0.037, Mann-Whitney test) as well as difference between GPs who have a recognized specialty and those who don't ( $\mathrm{p}=0.011$, Kruskall-Wallis). Physician with acquired specialty in general medicine have higher satisfaction.

\section{Job satisfaction of the workload}

Satisfaction with the workload is one of the lowest of all the surveyed items (mean $=38.2$ ). Dissatisfied are almost $50 \%$, when the satisfied are only $21 \%$ (Figure 3).

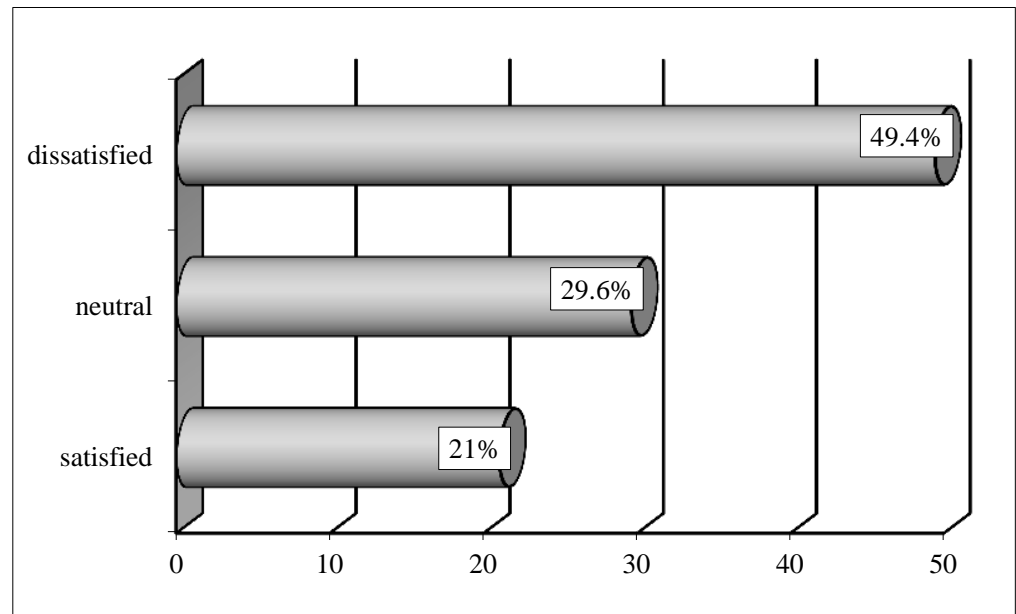

Figure 3. Satisfaction of the workload - \% of satisfied and \% of dissatisfied 
GPs have a varied workload comprising both medical and non-medical activities. Many of them voice concern about higher level of nonmedical problems they have to deal with. A weak correlation exists between workload satisfaction and practitioner's age $(r=0.144$ with nonparametric correlation analysis). There is also a statistically significant difference in this item depending on the location (urban or remote rural locations) of the medical practice $(\mathrm{p}=0.025$, MannWhitney test).

Job satisfaction of the physical working conditions

Satisfaction with working conditions is relatively high at mean $=54.8$. A fourth of the GPs are dissatisfied (Figure 4).

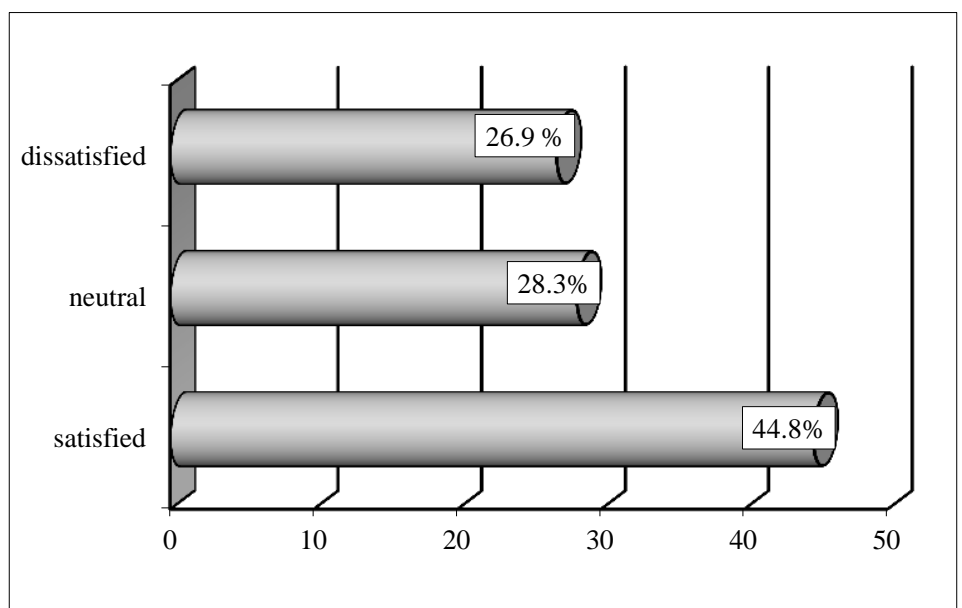

Figure 4. Satisfaction of the physical working conditions - \% of satisfied and \% of dissatisfied

This is the item with the highest standard deviation. Under the current health system in Bulgaria the GPs own their practices (20-22). They are incorporated as Ltd and do not receive a salary per se. The payments from the National Health Insurance Fund are spent as salaries for the medical personnel or reinvested in the practice (21). Some GPs tend to invest in the office and improve the conditions for patients and personnel. Some buy business property for use in the practice. Others rather tend to use money for personal needs. A large number of practitioners hire office space from the local communities at low rent. This happens mainly in the remote rural areas, where the working conditions are worse. The local authorities help the practices, striving to insure medical care for the residents in areas with low number of physicians. This study shows a statistically significant difference between male and female practitioners regarding working conditions $(\mathrm{p}=0.002$, Mann-Whitney). Males are more satisfied than females. There is also a weak correlation between working conditions and number of patients in the practice $(\mathrm{r}=0.133$, nonparametric correlation analysis).

Job satisfaction of the variety in the activities performed

Satisfaction with job variety is low (mean = 35). $57.8 \%$ are dissatisfied (Figure 5).

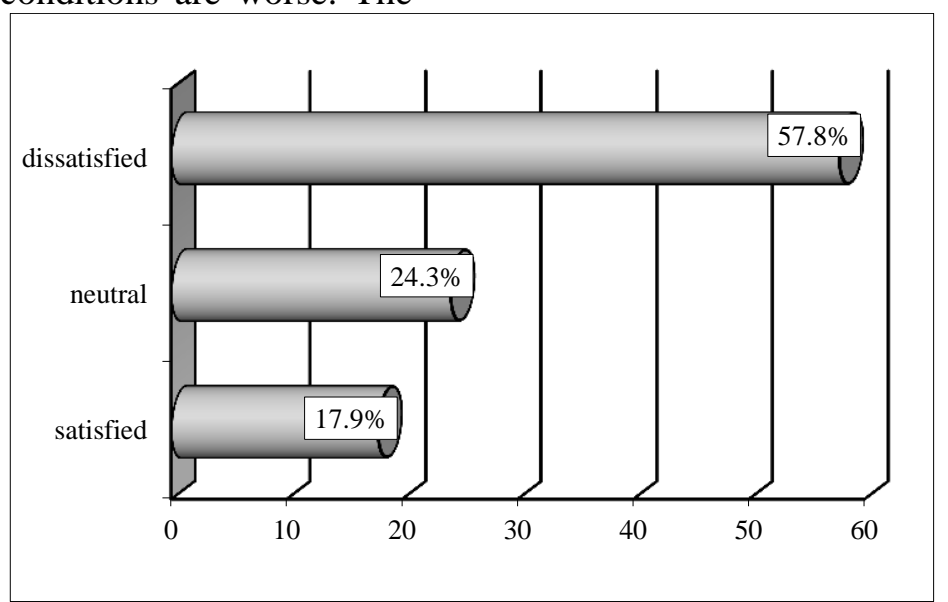

Figure 5. Satisfaction of the variety in the activities performed- $\%$ of satisfied and $\%$ of dissatisfied 
Primary care is characterized by a great variety of activities - first contact, attending the patient, subsequent coordination with other parts of the health system. Diagnosis and treatment, health care promotion and prophylaxis for the young, long term care and palliative care for the elderly - the scope and range of activities is pretty extended. This implies the GP "jumping" from one activity to another, gyrating between medical, social, and administrative functions. Not surprisingly, this item shows a large proportion of dissatisfaction
(22). There is a statistically significant difference in activity satisfaction between urban and rural practices $(\mathrm{p}=0.024$, KruskalWallis and $\mathrm{p}<0.05$, Dunn post hoc test) as well as a weak correlation between activity and practitioner's age $(r=0.135)$.

Job satisfaction of the professional knowledge and ability confidence

The mean score for this item is 52.4. The level of satisfaction is high (41.3\%) (Figure 6).

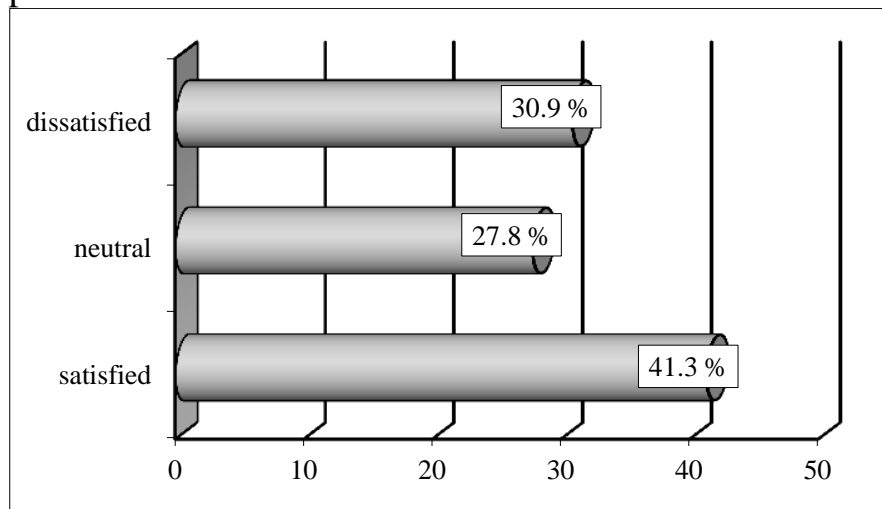

Figure 6. Satisfaction of the with professional knowledge and ability confidence - $\%$ of satisfied and $\%$ of dissatisfied

The confidence in professional abilities is an important factor for the practitioner's overall wellbeing. The GPs with acquired specialty (board certified) have higher confidence with their professional abilities compared to those without specialty. There is a statistical difference between the two groups $(p=0.003$, Kruskal-Wallis test). Males show higher satisfaction than female practitioners $(\mathrm{p}=$ 0.016, Mann-Whitney). Also noticeable is a weak negative correlation between professional abilities and age $(r=-0.159)$

Job satisfaction of the regulatory framework The satisfaction with the regulatory framework is the lowest of all items (mean $=34.9)$, while the dissatisfaction is the highest at $55.6 \%$ (Figure 7). The GPs in Bulgaria are paid by the National Health Insurance Fund and are required to comply with all its regulations or face sanctions. A lot of the practitioners feel of the regulations as a burden, useless and overreaching in many cases. Clearly the medical profession is a free profession and putting it in a rigid framework is loathed by most professionals as well as unavoidable in the modern world. There are no statistically significant findings for this item above the threshold of $p<0.05$, generally accepted in this study.

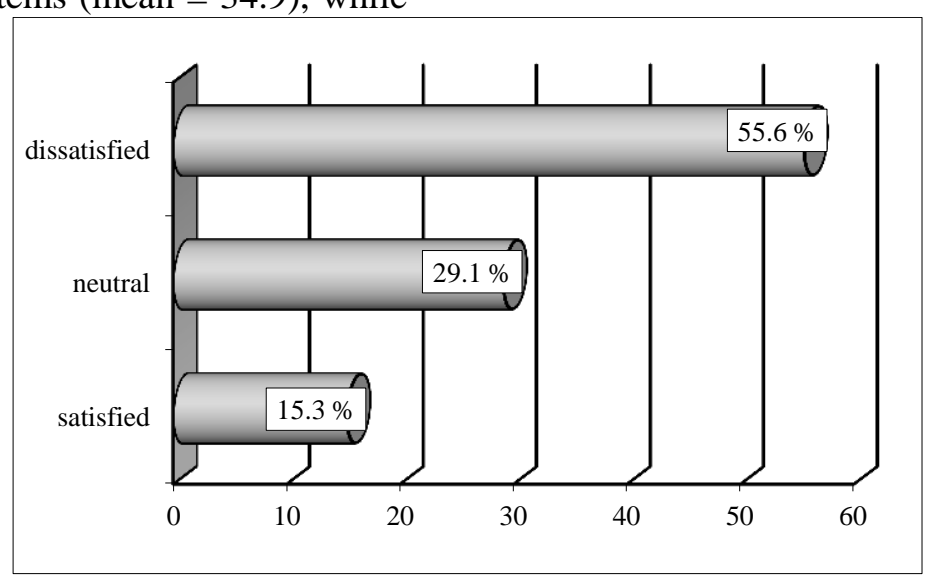

Figure 7. Satisfaction of the regulatory framework - $\%$ of satisfied and $\%$ of dissatisfied 
Job satisfaction of the continuous education and promotion opportunities

The GPs voice very high dissatisfaction (55.7 $\%)$ on this item similar to those of the regulatory framework $($ mean $=35.4)$. Here too there are no statistically significant findings. Practitioners point out specifically to the nonexistence of organized continuous education, except for the one provided by some pharmaceutical companies. GPs think of this as wrong and inadequate. Some consider the Physicians Union, as professional organization liable for organizing a system of continuous education and differentiating between professionals who care about their own development and those who do not (Figure 8).

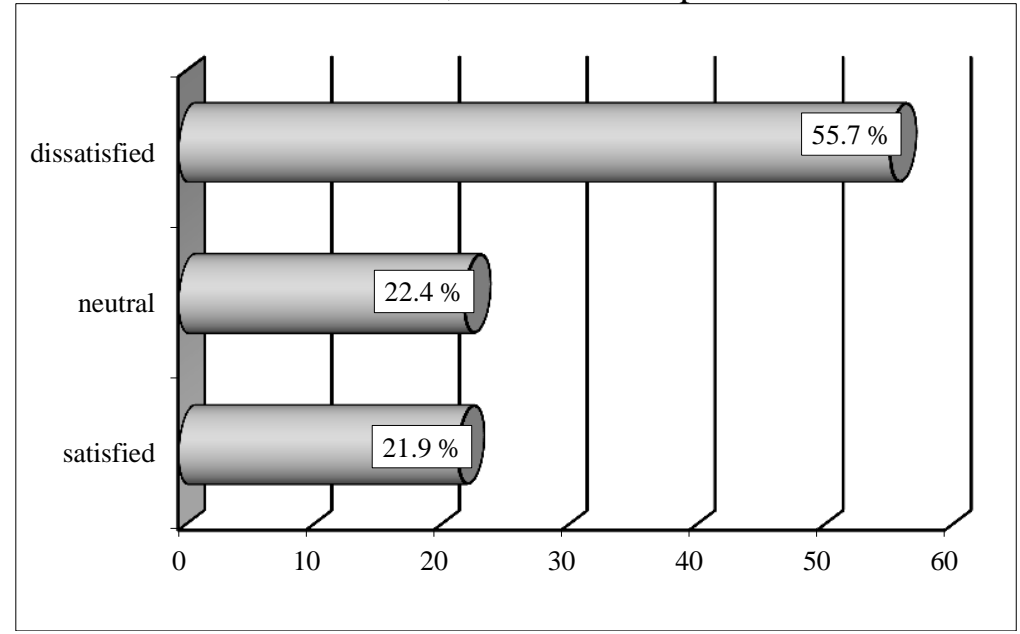

Figure 8. Satisfaction of the continuous education and promotion opportunities- $\%$ of satisfied and $\%$ of dissatisfied

\section{CONCLUSION}

For the first time in Bulgaria, the original toolkit for the study of professional satisfaction of general practitioners was implemented in the Stara Zagora region by applying a modified scale with good reliability. The modified WCW-scale for assessment of job satisfaction among physicians has high reliability and is used for the first time in Bulgaria. Satisfaction has a direct bearing on the careers of many medical professionals and repercussions on the future availability of medical professionals.

The dimensions of professional satisfaction were researched. Clinical freedom, defined as the possibility for the GPs to choose their method of treatment to their patients, is assessed as the most satisfying factor in general medical practice. The regulatory framework that must be followed is the factor that bears the greatest dissatisfaction in the work of general practitioners.

Studies of professional satisfaction of physicians are particularly important nowadays in relation to the emerging crisis with medical personnel. These studies may form the basis of policies for managing human resources in health care, because they identify unfavorable trends and provide guidance for decisions. The results may be interpreted as an early warning for negative trends in primary care and used for crafting future policies in human resources management of the healthcare system. All this knowledge and evidence should be used to support the sustainability and stability of the health system, because it is strategic area concerning the well-being of the nation.

\section{REFERENCES}

1. Spector P., Job satisfaction: application, assessment, causes and conseguences, Sage, London, 1997, available on: http://eiu.edu/social/iosyllabus.pdf.

2. Encyclopedia of Psychology and Behavioral Science, Nauka I izkustvo, 2008, p. 1512 (in Bulgarian)

3. Diaz-Serrano L., J.A Cabral Vieira, Low pay, higher pay and job satisfaction within the European Union: Empirical evidence from fourteen countries,IZA Discussion Papers No. 1558, Institute for the Study of Labour(IZA), 2005, available on: http://ideas.repec.org/p/iza/izadps/dp1558. htm

4. Cooper RA., T.E. Getzen, H.J. McKee, and P. Laud. 2002. Economic and Demographic Trends Signal an Impending Physician Shortage., Health Affairs 21:140-54.

5. Karabelyova S., Management and development of human potential, Sofia, Classics and style, 2004, p. 290 (in Bulgarian) 
6. Judge T., R. Ilies, Affect and Job Satisfaction: A Study of Their Relationship at Work and at Home, Journal of Applied Psychology, Vol 89(4), Aug 2004, 661673.

7. Warr P, Cook J, Wall T. Scales for measurement of some work attitudes.and aspects of psychological well- being. $J$ Occupat Psychol 1979; 52: 129-148.

8. Sibbald Bonnie, C.Bojke, Gneral Practitioner job satisfaction in England, National Primary care Research and Development Centre, 2002, available on: http://www.population-

health.manchester.ac.uk.

9. Sibbald B., I. Enzer, C. Cooper et al., GP satisfaction in 1987,1990 and 1998: lessons for the future? Family Practice 2000: 364-371.

10. Sibbald B. C. Bojke, H. Gravelle, National survey of job satisfaction and retiremen tintentions among general practitioners in England, BMJ, vol.326:22,2003, available on:http://www.ncbi.nlm.nih.gov/pmc/articl es/PMC

11. Simoens St., A. Scot, B. Sibbald, C. Bojke, $\mathrm{H}$. Gravelle, Job satisfaction, intentions to quit and the retention of GPs in England and Scotlad, National Primary care Research and Development Centre, 2002, HERU Discussion Paper, available on: http://citeseerx.ist.psu.edu/viewdoc.

12. Bovier P., T. Perneger, Predictors of work satisfactions among physiciams, European journal of Public Health, 2003;13, 299305.

13. Buciuniene I., A. Blazeviciene, E. Bliudziute, Health care reform and job satisfaction of primary health care physicians in Lithuania. BMC Fam Pract 2005, 6(1): 10-15.

14. Cooper C, U. Rout, B. Faragher, Mental health, job satisfaction, and job stress among general ractitioners, $B M J$ 1989;298:366-70.
PARASHKEVOVA B., et al.

15. Nylenna M., P. Gulbrandsen, R. Forde, O. Aasland, Job satisfaction among Norwegian,Scandinavian Journal of Primary Health Care, 2005;23:1989-2002.

16. Thistlethwaite J. , M. Kidd, S. Leeder, Enhancing the choice of general practice as a career, Australian Family Physician, Vol. 37, No. 11, November 2008: 964-968.

17. Platikanova M., S. Alekova, V. Slavova. Stress and manifestations of fatigue in the daily activities of the general practitioner from the Stara Zagora region. Sat. Papers and abstracts, II Conference of the Association of General Practitioners / Family Medicine from Southeast Europe, Bulgaria, Plovdiv, November 10-13, 2011, Sofia: NSOPLB, 2011: p.17

18. B. Parashkevova, Sv. Dimitrova J. Marinova, Sl. Jordanova, K. Peeva, G. Chamova, Attitude and behavior of General practitioners to homeopathy,Trakia Journal of Sciences, Supplement 1, 2005: 136-138

19. B. Parashkevova, J.Marinova, General practitioners' career characteristics and factors: results from an empirical study, General Medicine, vol.XVIII, 2016/2: 2833

20. Parashkevova B., Y.Marinova, S.Simeonov, M. Encheva, General Practitioners: a Key Resource in Primary Health Care (First announcement), Social Medicine, 2011/3: 27-31

21. Parashkevova B., N. Penev, I. Nencheva, S. Simeonov, A. Zdraveska, J. Marinova, Financing Management of General Practitioners Practices in Bulgaria: Features and Challenges, Trakia Journal of Sciences, Vol. 15, Suppl. 1, pp. 247-251, 2017 ,

22. Tyrnovska, M., R. Dimova, A. Dzhurkova. Job satisfaction, professional image and loyalty to the specialty "general practitioner". General Med., 17, 2015, № $1,8-12$ 